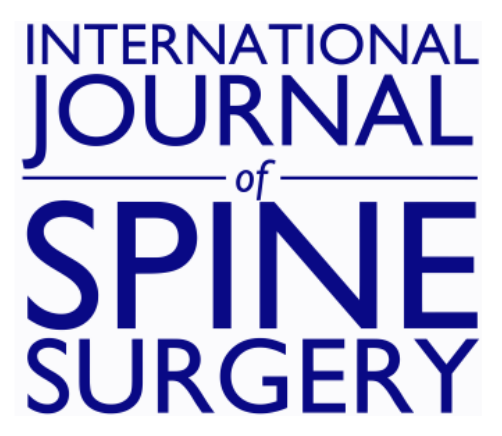

\title{
Can We Predict the Progression of Vertebral Collapse in Conservative Treatment of Osteoporotic Vertebral Fractures? A 3-Year Retrospective Study of 180 Patients From the Emergency Department
}

\author{
MARCO MURATORE, ANDREA FERRERA, ALESSANDRO MASSE and ALESSANDRO \\ BISTOLFI
}

Int J Spine Surg 2020, 14 (4) 641-648

doi: https://doi.org/10.14444/7084

http://ijssurgery.com/content/14/4/641

This information is current as of April 25, 2023.

Email Alerts Receive free email-alerts when new articles cite this article. Sign up at:

http://ijssurgery.com/alerts 


\title{
Can We Predict the Progression of Vertebral Collapse in Conservative Treatment of Osteoporotic Vertebral Fractures? A 3-Year Retrospective Study of 180 Patients From the Emergency Department
}

\author{
MARCO MURATORE, MD,${ }^{1}$ ANDREA FERRERA ${ }^{2}$ ALESSANDRO MASSE, MD PROF CHIEF,${ }^{1,2}$ \\ ALESSANDRO BISTOLFI, MD ${ }^{1}$ \\ ${ }^{I}$ Hospital Città della Salute e della Scienza, Department of Orthopaedics, Traumatology, and Rehabilitation, Orthopaedic and Trauma Centre, CTO, Turin, Italy, \\ ${ }^{2}$ University of the Studies of Turin, School of Orthopaedics and Traumatology, Turin, Italy
}

\begin{abstract}
Background: Osteoporotic vertebral fractures (OVFs) have a high incidence in the elderly population and are usually treated conservatively with good outcomes. Nevertheless, failure of the conservative treatment may lead to serious complications. The aim of the study is to identify clinical, radiographic, and magnetic resonance imaging findings potentially related to the failure of the conservative treatment of OVFs.

Methods: Data from 620 patients treated in the emergency department for vertebral fracture from 2014 to 2016 were analyzed; after patient identification and inclusion criteria, only fresh OVFs of patients older than 65 years have been included. Main outcome measurements were vertebral collapse, fracture shape types, and progression of vertebral collapse. A progression of vertebral collapse $>100 \%$ was taken as an independent variable to underline the statistically significant difference among the risk factors.

Results: A total of 180 patients ( 138 women; $42 \mathrm{men}$ ) and 200 OVFs were analyzed (mean age $=77$ years, range $=$ 65-94 years). Potential risks factors for the progression of vertebral collapse $>100 \%$ were found when fractures occurred in the thoraco-lumbar junction. The swelling type and the bow-shaped type showed higher risk of vertebral collapse, while the concave was the most stable type of fracture with good prognosis. Traumatic fractures had lower risks of fracture progression compared to nontraumatic fractures (eg, fractures after an effort). A linear black signal pattern on short inversion time inversion recovery findings of magnetic resonance imaging corresponded to a risk of progression of the vertebral collapse.
\end{abstract}

Conclusions: Thoraco-lumbar fractures, swelling and bow-shaped fractures, and a linear black area at MR are negative prognostic factors for the failure of conservative treatment.

Level of Evidence: 4.

Clinical Relevance: The identification of negative prognostic factors may lead to different strategies of treatment to prevent vertebral collapse or failure of conservative treatment.

Other \& Special Categories

Keywords: risk factors, kyphotic deformity, conservative treatment failure

\section{INTRODUCTION}

Osteoporotic vertebral fractures (OVFs) have a high incidence in the elderly population, and they are strongly associated with age, female sex, body mass index, weight rising, etc. ${ }^{1,2}$ The number of patents is increasing, and it is becoming an important socioeconomic health issue. They are usually treated conservatively with a bed rest period, pain control with analgesics, bracing, bisphosphonates, and early rehabilitation. ${ }^{3}$ The outcomes of conservative treatment are usually good, and the majority of vertebral fractures heal with functional recovery and without deformities or pain. The complications that may occur during conservative treatment of OVFs are progression of vertebral collapse, pseudoarthrosis, hyperkyphosis, and neurologic deficits. Even if they are rare, these may cause prolonged back pain, strong impairment of daily living activities, and reduced quality of life, resulting in the failure of conservative treatment. ${ }^{4}$ Recently, the importance of investigating risk factors associated with the onset of these complications has risen, as alternative treatments such as 
kyphoplasty or vertebroplasty-rather than conservative treatment-might be taken into account in the poor prognosis of OVF. Among these complications, the most recurring is surely the progression of vertebral collapse. Now only few studies have analyzed its pathogenesis, and indeed, the mechanism of its onset remains partially unclear ${ }^{5-11}$.

This study was designed to identify clinical, radiographic, and magnetic resonance imaging (MRI) findings related to the progression of vertebral collapse and prolonged back pain. The hypothesis was that the identification of negative prognostic factors may lead to different strategies of treatment to prevent vertebral collapse or failure of conservative treatment.

\section{MATERIALS AND METHODS}

\section{Patient Population}

The electronic databases SynchroMed (Version 3.1.75RC1; Synchro-Med, Bolzano, Italy) and Synapse (Version 3.2.15111) developed by Fuji Medical System, which contains the data of all patients admitted to our emergency department, were checked. The period ranged from January 2014 to December 2016. The program allows searches by the diagnostic fields belonging to the International Classification of Diseases, Ninth Revision, Clinical Modification. The diagnostic codes used were 805.2 (closed fracture of thoracic vertebra without mention of spinal cord injury), 805.4 (closed fracture of lumbar vertebra without mention of spinal cord injury), 733.10 (unspecified vertebral fracture), 733.10 (pathologic vertebral fracture), 806.2 (thoracic vertebral fracture with spinal cord injury), and 8064 (lumbar vertebral fracture with spinal cord injury).

Inclusion criteria of the study were (1) patients older than 65 years with diagnosis of osteoporosis (T-score $<-2,5)$, (2) affected by fresh $\mathrm{OVF}(\mathrm{s}),(3)$ admitted to our emergency department no longer than 7 or 14 days from the onset of pain, and (4) conservative treatment at the hospital discharge.

Exclusion criteria were (1) fractures caused by car accident or precipitation trauma, (2) infections, (3) metastasis, (4) chronic use of corticosteroids, (5) misdiagnosed fractures (older than 14 days), (6) fractures treated by vertebroplasty or kyphoplasty, or (7) fractures treated by open surgery. Clinical data and radiographs included in the database were examined after patient identification.

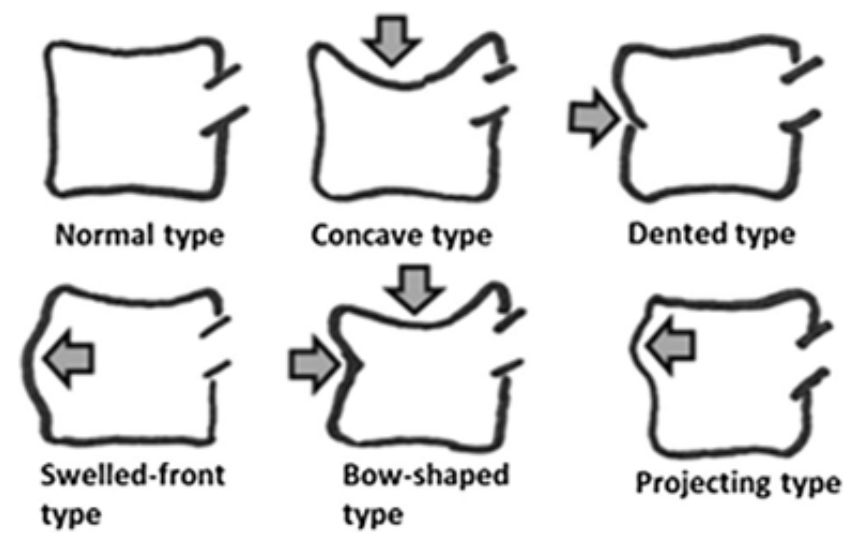

Figure 1. Sugita et $\mathrm{al}^{12}$ new classification of early osteoporotic vertebral fractures. $^{14}$

\section{Study Protocol and Imaging Parameters}

At the time of the enrollment, patients were examined by plain radiograph of the painful segment of the spine in 2 projections, latero-lateral and antero-posterior. The diagnosis of fresh OVF(s) was made by acute back pain and deformed vertebra(e) on the standard x-ray examination. The vertebral collapse was calculated by dividing the height of the fractured vertebra at the point of the maximum loss by the mean height of the adjacent vertebrae in the lateral images. Vertebral fractures were divided into thoracic fractures (from $\mathrm{T} 1$ to T10), thoraco-lumbar junction fractures (from T11 to L2), and lumbar fractures (from L3 to L5). As for the shape, vertebral fractures were classified into 5 types, according to some elements taken from Sugita et al $^{12}$ ("swelling," "bow-shaped," and "concave" fractures types; Figure 1) and Genant et $\mathrm{al}^{13}$ classifications ("biconcave" and "wedge" fractures types). At the initial examination, the amount of back pain was assessed by the visual analog scale (VAS). The scale ranged from 0 to 10 , where the 0 score means no pain, and 10 means unbearable pain. Also, the pathogenic mechanism was taken into account, as the patients were divided in those whose fractures were caused by an accidental fall with direct trauma and those whose fractures were not caused by a direct trauma (lifting objects, standing up from the chair or the couch, sneezing, coughing, etc.). As Omi et $\mathrm{al}^{11}$ performed in their study, for those who underwent MRI study during the followup period, short inversion time inversion recovery (STIR) findings were evaluated, and linear or nonlinear black signal areas in the fractured vertebra were analyzed (Figure 2). At the 5-month follow-up examination, they were examined again 


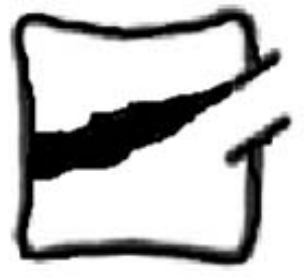

Linear black signal area

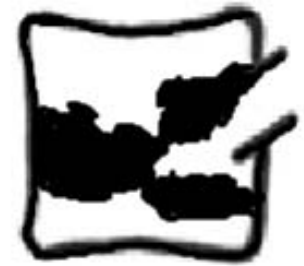

Non-linear black signal area

Figure 2. Linear black signal was defined as linear black signal area of more than half the length of a fractured vertebral body in magnetic resonance imaging short inversion time inversion recovery images, while the nonlinear black signal area group was defined when the pattern was not linear. ${ }^{11}$

by plain radiography. The vertebral collapse was calculated again by dividing the height of the fractured vertebra at the point of the maximum loss by the mean height of the adjacent vertebrae in the lateral images. The progression of the vertebral collapse was calculated and expressed as a percentage variation. It was obtained by subtracting the vertebral collapse at the initial examination from the collapse calculated at the follow-up examination, and the result was then divided by the vertebral collapse at initial examination $^{11}$ (Figure 3). A value of progression of vertebral collapse $>100 \%$ was taken as an independent variable in order to underline any statistically significant difference among the considered risk factors.

The VAS score was revaluated at the follow-up examination. The changes in these scores and ratios in the observation period were investigated with the

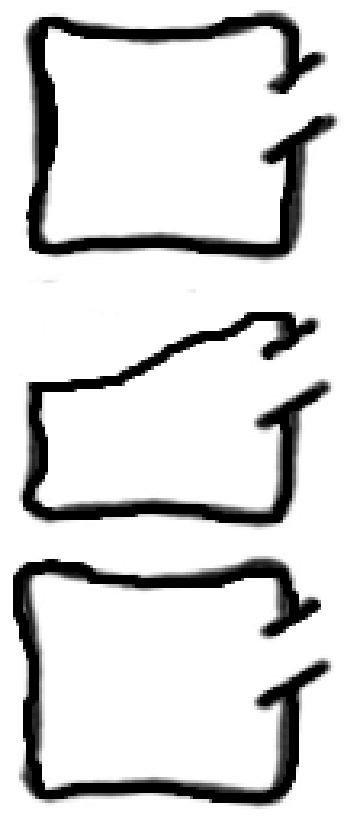

Figure 3. Evaluation of the vertebral collapse and its progression. Vertebral collapse $(\%)=\frac{\text { Height of the affected vertebra }}{\text { Sum of the height of superior and inferior vertebrae } \times 0.5} \times 100$. aim to determine if the progression of vertebral collapse and the worsening of the back pain were associated to the level of the fracture, the shape, the pathogenic mechanism, and the MR pattern.

\section{Statistical Analysis}

To underline the association between level of the fracture, shape, and MRI pattern, a univariate regression analysis was performed with the progression of the vertebral collapse $>100 \%$ at 5 months as an outcome. Odd ratios (ORs) and their 95\% confidence intervals (CIs) were calculated for every variable as an approximation of the relative risks. Progression of vertebral collapse $>100 \%$ was defined as the response variable. A value of $P<$ .05 was considered statistically significant.

$$
\begin{gathered}
\mathrm{OR}(a / b) /(c / d)=(a \times d) /(b \times c) . \\
\mathrm{SE}\{\ln (\mathrm{OR})\}=\sqrt{(1 / a+1 / b+1 / c+1 / d) .} \\
95 \% \mathrm{CI}=\exp \{\ln (\mathrm{OR})-1.96 \times \mathrm{SE}[\ln (\mathrm{OR})]\} \text { to } \\
\exp \{\ln (\mathrm{OR})+1.96 \times \mathrm{SE}[\ln (\mathrm{OR})]\} .
\end{gathered}
$$

Differences in the VAS scores between the shape, level of fracture, and MRI pattern groups were assessed by a $t$ test. Values of $P<.05$ were considered statistically significant. All statistical analyses were performed using SPSS software (version 22.0; IBM SPSS Statistics, IBM Segrate, Milano, Italy).

\section{Compliance with Ethical Standards}

Patients gave their consent; the study was conducted in accordance with the ethical standards. The authors declare that they have no specific conflict of interest, that they did not receive funding, and that the study meets the ethical standards of the journal.

\section{RESULTS}

A total of 620 patients were admitted to our emergency department with the diagnosis of vertebral fracture. Between them, 130 were excluded because of age, and 125 were excluded because the fractures were caused by high energy trauma or neoplastic or infective diseases. In addition, 105 patients were excluded because the initial radiograph was missing because of a previous passage from another emergency department to ours. A total of 60 did not complete the follow-up exami- 


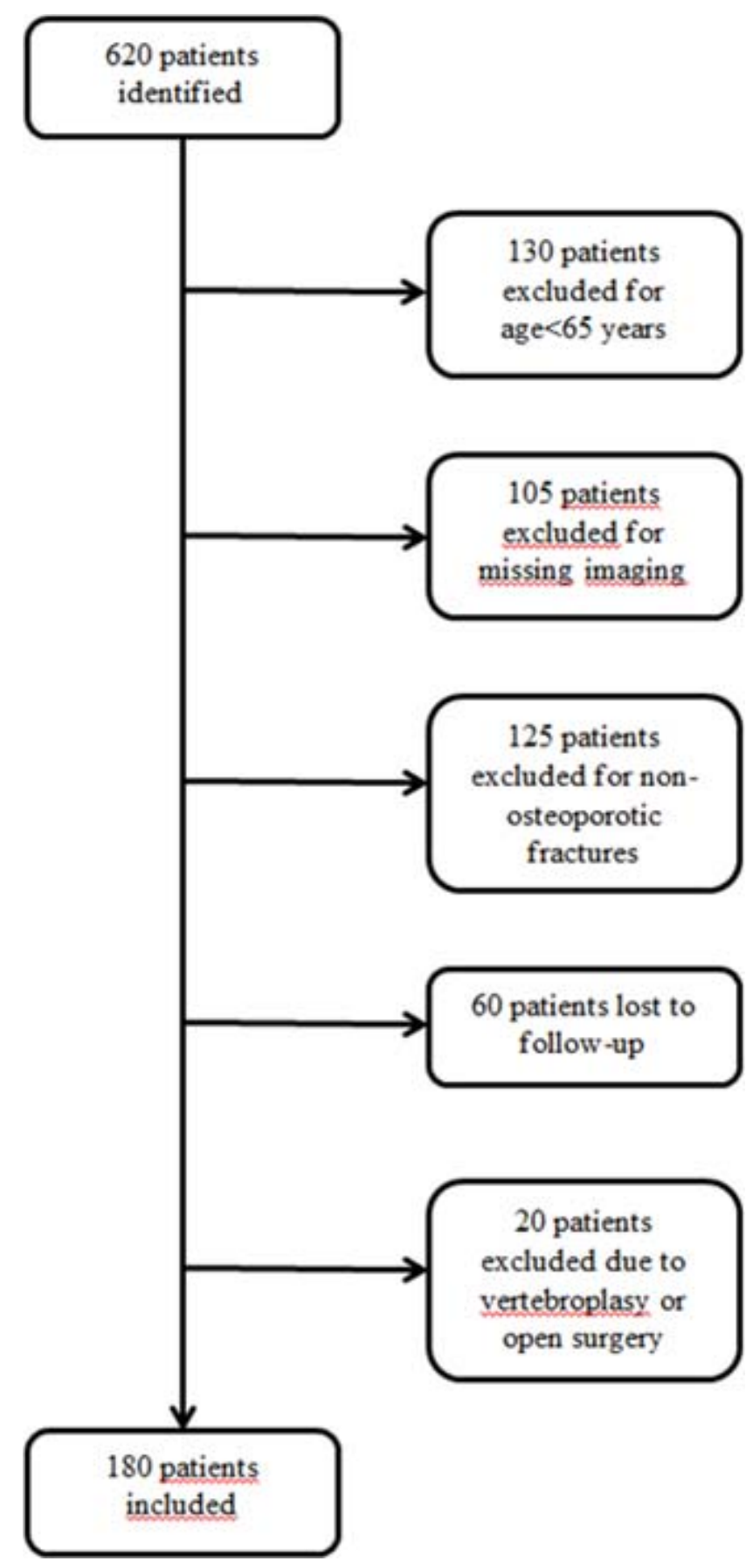

Figure 4. Flowchart diagram showing patient selection process.

nation, and therefore, they were excluded, as they were lost to follow up. A total of 20 patients were excluded, as they were treated with open surgery or vertebroplasty because of the failure of conservative treatment, and they did not complete the follow up. As a result, 180 patients (138 women and 42 men) with 200 OVFs completed the follow up with all the required data and were included in the study. Figure 4 illustrates the patient selection process through a flowchart diagram. All of them were outpatients and

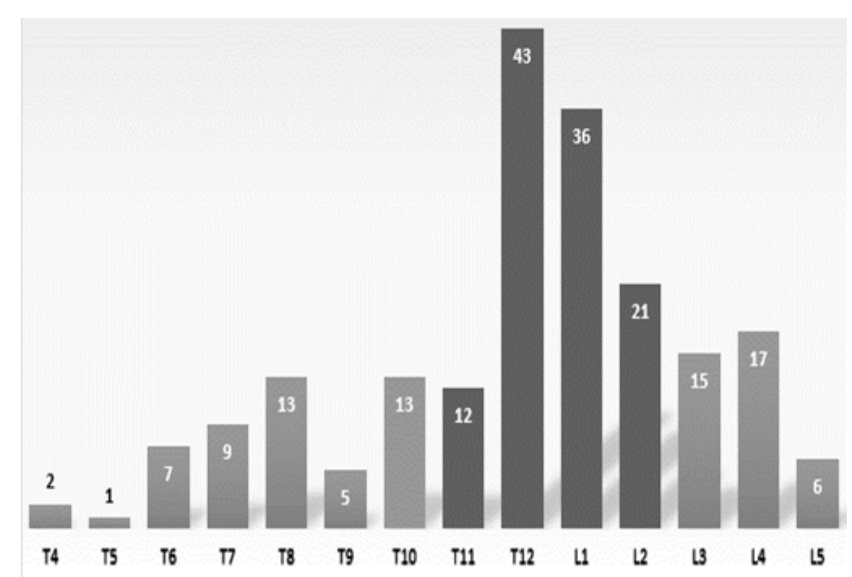

Figure 5. Distribution of the vertebral fractures across the spine.

were treated conservatively with Jewitt Brace, CAMP C-35, nonsteroidal anti-inflammatory drugs, bisphosphonates, and early rehabilitation.

The age at the time of the enrollment ranged from 65 to 94 years, with a mean age of 77 years, while the follow-up length was 5 months. In this cohort, many vertebral fractures occurred in the thoracolumbar junction (T10-L2) and in the midthoracic region (T7-T8). Furthermore, the majority of the fractures involved T12 (22\%), as shown in Figure 5. As for the shape, most observed were the "concave" and "wedge" ones; these were considered as the most stable types of fractures, while the others represent only a minor quota in the population studied. Table 1 shows the distribution of the 5 types of fractures among all levels of the spine.

A total of 20 patients were excluded from this study, as they were treated with early vertebroplasty, and they did not complete the radiographic follow up. Specifically, 13 of them suffered from persistent pain that did not respond to conservative treatment, 5 of them showed an intravertebral vacuum cleft (IVC) in the fractured vertebrae, while 2 of them showed a regional kyphosis angle $>50 \%$. The characteristics of the fractures of these 20 patients are collected in Table 2 .

In order to seek potential associations for the progression of vertebral collapse $>100 \%$ in the OVFs, according to univariate analysis, higher ORs were found when fractures occurred in the thoracolumbar junction than those which occurred in the other regions of the spine. High ORs were also found when thoraco-lumbar junction fractures were compared to those which occurred only in thoracic region and only in the lumbar region. The VAS score showed a statistically significant increase of 
Table 1. Type of fracture distribution across the spine.

\begin{tabular}{lcccccr}
\hline & \multicolumn{5}{c}{ Type of Fracture } & \\
\cline { 2 - 6 } Level & Wedge & Concave & Biconcave & Bow-Shaped & Swelling & Total \\
\hline T4 & 2 & 0 & 0 & 0 & 0 & 2 \\
T5 & 1 & 0 & 0 & 0 & 0 & 1 \\
T6 & 7 & 0 & 0 & 0 & 0 & 7 \\
T7 & 8 & 1 & 0 & 0 & 0 & 9 \\
T8 & 8 & 3 & 2 & 0 & 0 & 13 \\
T9 & 3 & 2 & 0 & 0 & 0 & 5 \\
T10 & 3 & 8 & 0 & 1 & 1 & 13 \\
T11 & 4 & 4 & 2 & 1 & 1 & 12 \\
T12 & 9 & 21 & 5 & 5 & 3 & 43 \\
L1 & 2 & 23 & 1 & 8 & 2 & 36 \\
L2 & 1 & 13 & 0 & 5 & 2 & 21 \\
L3 & 1 & 11 & 3 & 0 & 0 & 15 \\
L4 & 2 & 13 & 2 & 0 & 0 & 17 \\
L5 & 0 & 6 & 0 & 0 & 0 & 6 \\
Total & 51 & 105 & 15 & 20 & 9 & 200 \\
\hline
\end{tabular}

back pain in thoracolumbar junction fractures, both in the enrollment exam and at the follow-up examination, than fractures of the other levels of the spine and only lumbar and only thoracic vertebral fractures.

As for the shape, all 9 patients with swelling and 10 patients out of 20 with bow-shaped type underwent a $>100 \%$ progression of vertebral collapse. The other fracture shapes showed a low percentage of progression of vertebral collapse, and among them, the concave type was the most stable one with good prognosis, as already noted by Sugita et $\mathrm{al}^{12}$ (Table 3).

High ORs were found when swelling and bowshaped fractures were compared to concave fractures. On the other hand, low ORs were found when the wedge and biconcave fractures were compared to the concave one. Moreover, no statistically significant difference was underlined $(P>.05)$. As for the VAS score, a statistically significant increase of back pain, both in enrollment and in the followup examination, was noticed when swelling was compared with concave fractures. Additionally, back pain was increased in the follow-up examina-

Table 2. Type of fracture distribution of the 20 patients excluded from the study.

\begin{tabular}{|c|c|c|c|c|c|c|}
\hline \multirow[b]{2}{*}{ Level } & \multicolumn{5}{|c|}{ Type of Fracture } & \multirow[b]{2}{*}{ Total } \\
\hline & Wedge & Concave & Biconcave & Bow-Shaped & Swelling & \\
\hline T9 & 1 & & & & & 1 \\
\hline $\mathrm{T} 10$ & & 4 & & & & 4 \\
\hline T11 & 2 & & & & 2 & 4 \\
\hline $\mathrm{T} 12$ & & 3 & 1 & 1 & & 5 \\
\hline L1 & & & 1 & & & 1 \\
\hline L2 & & 2 & & & & 2 \\
\hline L3 & 2 & & & 1 & & 3 \\
\hline Total & 5 & 9 & 2 & 2 & 2 & 20 \\
\hline
\end{tabular}

Table 3. Shape of fractures and progression of vertebral collapse.

\begin{tabular}{lccc}
\hline Type & $\begin{array}{c}\text { Vertebrae } \\
\text { Affected }\end{array}$ & $\begin{array}{c}\text { Vertebrae } \\
\text { Collapsed } \mathbf{> 1 0 0 \%}\end{array}$ & $\begin{array}{c}\text { Percentage } \\
(\mathbf{\%})\end{array}$ \\
\hline Swelling & 9 & 9 & 100 \\
Bow-shaped & 20 & 10 & 50 \\
Biconcave & 15 & 3 & 20 \\
Wedge & 51 & 10 & 19.6 \\
Concave & 105 & 12 & 11.4 \\
\hline
\end{tabular}

tion when bow-shaped fractures are compared with concave fractures.

As for the pathologic mechanism, 146 patients reported an accidental fall to be the cause of the fractures, while in the other 54 patients, the onset of pain was related to nontraumatic activities such as lifting heavy objects, standing up, coughing, and sneezing. Low ORs were found when comparing fractures due to trauma with nontraumatic fractures, and the difference was not significant.

In the population studied, only 52 patients underwent a MRI study in addition to the routine plain radiographic study. Among the 22 of them who showed a linear black signal pattern on STIR findings, 14 underwent a $>100 \%$ progression of vertebral collapse, while 6 out of 30 who showed a nonlinear black signal had the same outcome. High ORs were found when comparing these STIR patterns, and the difference was statistically significant. The VAS score showed a statistically significant difference in the amount of back pain, both in enrollment and in the follow-up examination, when linear fractures were compared with nonlinear black area fractures (Table 4).

\section{DISCUSSION}

The progression of vertebral collapse represents a common thread among all other complications in the conservative treatment of OVFs. Our results correlate the risk factors linked to the localization, the shape of the fracture, the pathologic mechanisms that caused them, and the MRI patterns studied with the STIR technique to predict the prognosis of the OVFs at an early stage. An additional aim was to evaluate some of the risk factors previously shown in the literature. ${ }^{14}$ The study has several limitations such as patients lost to follow up and patients lost due to incomplete imaging. Also, it is not prospective, and it does not have a control group.

Baudouin et $\mathrm{al}^{5}$ assumed that vertebral collapse might be the direct consequence of a necrotic ischemic process which affects the vertebral bony 
Table 4. Association with progression of vertebral collapse $>100 \%$. Parameter analysis.

\begin{tabular}{|c|c|c|c|c|c|c|}
\hline & OR (95\% CI); z Value & $P$ Value & VAS Enrollment & $P$ Value & VAS Follow Up & $P$ Value \\
\hline \multicolumn{7}{|l|}{ Level } \\
\hline $\begin{array}{l}\text { Thoracolumbar junction } \\
\text { (vs other levels) }\end{array}$ & 4.0595 (1.6215-10.1630); 2.992 & .0028 & $7 \pm 1.7($ vs $6 \pm 2)$ & .008 & $2.5 \pm 1.8(\mathrm{vs} 2 \pm 1.5)$ & .0374 \\
\hline $\begin{array}{l}\text { Thoracolumbar junction } \\
\text { (vs thoracic fractures) }\end{array}$ & 4.7619 (1.3925-16.2837); 2.488 & .0129 & $7 \pm 1.7($ vs $6.2 \pm 1.9)$ & .01 & $2.5 \pm 1.8($ vs $1.8 \pm 1.2)$ & .01 \\
\hline $\begin{array}{l}\text { Thoracolumbar junction } \\
\text { (vs lumbar fractures) }\end{array}$ & 3.6190 (1.0480-12.4979); 2.034 & .0419 & $7 \pm 1.7($ vs $6 \pm 2)$ & .002 & $2.5 \pm 1.8($ vs $2.3 \pm 1)$ & .51 \\
\hline \multicolumn{7}{|l|}{ Shape (vs concave fractures type) } \\
\hline Swelling fractures type & 8.7500 (2.9121-26.2913); 3.864 & .0001 & $7.8 \pm 1.8($ vs $6.8 \pm 1)$ & $<.0001$ & $4 \pm 2($ vs $2.2 \pm 1.8)$ & .005 \\
\hline Bow*shaped fractures type & 4.3750 (1.6653-11.4938); 2.995 & .0027 & $7.2 \pm 2($ vs $6.8 \pm 1)$ & .177 & $3.4 \pm 1.5($ vs $2.2 \pm 1.8)$ & .006 \\
\hline Biconcave fractures type & 2.1875 (0.5399-8.8625); 1.097 & .2728 & $6.6 \pm 2.1($ vs $6.8 \pm 1)$ & .54 & $2.5 \pm 1($ vs $2.2 \pm 1.8)$ & .52 \\
\hline Wedge fractures type & $1.7157(0.6951-4.2345) ; 1.171$ & .2416 & $7 \pm 1.3($ vs $6.8 \pm 1)$ & .29 & $2 \pm 1.9($ vs $2.2 \pm 1.8)$ & .53 \\
\hline \multicolumn{7}{|l|}{ Pathogenic mechanism } \\
\hline $\begin{array}{l}\text { Falling (vs atraumatic fractures) } \\
\text { MRI STIR pattern }\end{array}$ & $0.9403(0.3796-2.3294) ; 0.133$ & .8942 & $6.8 \pm 1.5($ vs $6.6 \pm 1.2)$ & .37 & $3 \pm 1.2($ vs $2.8 \pm 1.2)$ & .39 \\
\hline $\begin{array}{l}\text { Linear black area (vs nonlinear } \\
\text { black area) }\end{array}$ & $5.7273(1.0217-3.2104) ; 1.984$ & .0472 & $7.4 \pm 2($ vs $6.4 \pm 1.6)$ & .05 & $3.4 \pm 2.1($ vs $2.3 \pm 1.6)$ & .03 \\
\hline
\end{tabular}

Abbreviations: CI, confidence interval; MRI, magnetic resonance imaging; OR, odds ratio; STIR, short inversion time inversion recovery; VAS, visual analog scale.

trabeculae and manifests itself with the so-called IVC. This hypothesis was also supported by authors of other studies that demonstrated the presence of necrosis in the affected vertebrae with bone biopsy. ${ }^{6,7}$ On the contrary, Antonacci et $\mathrm{al}^{8}$ demonstrated, thanks to histologic studies, the presence of bone necrosis both in noncomplicated vertebral fractures and even in nonfractured osteoporotic vertebrae. Therefore, according to these authors, bone necrosis might represent a nonspecific finding. Other authors reported cases of late vertebral collapse due to an impaired healing of the fracture, which caused a nonunion and a segmental instability of the affected vertebrae. $^{9}$ The instability, with the assistance of other external factors, such as inadequate bracing or lack of treatment compliance by the patients, may worsen the damage against the vertebra and further delay the healing process. Ito et $\mathrm{al}^{10}$ tried to find a common ground between the vascular and biomechanical theories, assuming that the vertebral collapse begins with the IVC sign, that may represent a trabecular defect caused by the fracture, which subsequently expands from the anterior wall of the vertebral body. This evolution is helped by factors that impair the healing process such as the lack of blood supply, cells, and growth factors. Therefore, an important instability creates across the entire trabecular thread which supports the vertebral body. Contemporarily, both the forces that weigh normally on the compromised structure and the continuous dynamic stress lead to the progression of vertebral collapse. Over the last several years, few authors considered the thoracolumbar junction as a risk factor for the progression of vertebral collapse. ${ }^{15} \mathrm{Ha}$ and $\mathrm{Kim}^{16}$ tried to compare 2 groups of patients who underwent a progression of vertebral collapse of $<15 \%$ and $>15 \%$, respectively, during the 6 months of follow up. No significant difference was found, but the results might be influenced by the definition of progression of vertebral collapse given by the same authors or by the low threshold of vertebral height loss taken as a comparison between the 2 groups.

On the other hand, we have demonstrated that fractures that involve the thoraco-lumbar junction are more likely to undergo a progression of vertebral collapse $>100 \%$ than fractures involving the lumbar and the thoracic spine. Usually, the thoraco-lumbar junction refers to T12 and L1 vertebrae, but in this study, we included T11 and L2, as also these segments play a primary role in the transition from the thoracic to the lumbar spine. The thoracic spine is linked to the sternum and the rib cage, which make this region stiffer and help the spine to bear part of the weight. Therefore, an important progression of vertebral collapse here is rare. Otherwise, the lumbar spine bears a greater static and dynamic load, and its flexibility increases gradually as the distance to the rib cage increases. Moreover, in the osteoporotic spine, the decrease of the intravertebral discs thickness, the hypotonia and hypotrophia of back muscles, and the dorsal kyphosis cause an anterior shift of the center of gravity with an increase of compressive forces at the expense of the thoraco-lumbar junction. All these factors contribute to the significant worsening of vertebral collapse and of back pain in this region compared to the other levels.

The progression of vertebral collapse in the different types of fractures is scarcely underlined 
in the literature. Sugita et al ${ }^{12}$ identified 2 groups of fracture shapes, with good and bad prognosis, respectively, underlining a significant difference in vertebral collapse between them. In this study, the authors considered some of the fracture shapes described by Sugita et $\mathrm{al}^{12}$ and Genant et al, ${ }^{13}$ demonstrating that swelling and bow-shaped types are strongly linked to the progression of vertebral collapse $>100 \%$. This difference might be related to the 3 columns theory of Denis et al, ${ }^{17}$ as probably the swelling and bow-shaped types of fractures involve the anterior but also the middle column, which is responsible for vertebral stability and represents a high risk factor for vertebral collapse and pseudoarthrosis. Additionally, the swelling type might be related to damage of the arteries that supply the vertebral body, causing a necrotic ischemic process with edema, which is responsible for the bulging area noticeable on the anterior wall. $^{12}$

As for the pathologic mechanism, we have highlighted that the progression of vertebral collapse in patients whose fractures were due to an accidental fall was smaller than those whose fractures were not related to trauma. The difference was not significant, and it was paradoxical at first sight, but it is conceivable that the nontrauma fractures might have occurred in strongly compromised vertebrae which led to further collapse.

Short inversion time inversion recovery sequences are often used in the clinical routine ${ }^{18,19}$ and might be a useful tool to predict the prognosis of vertebral fracture at an early stage. Few patients underwent MRI studies in addition to routine plain radiographic studies, and probably, the results were at the lower limits of significance due to the low number of cases analyzed. The pattern defined as linear black area represents widespread damage of the bone and the trabeculae; its linear shape causes a strong structural instability which interferes with the healing process and leads to progression of vertebral collapse.

The clinical impact of this study is that the onset of progression of vertebral collapse and the failure of conservative treatment is strongly associated with the worsening of patient clinical status, in which they are forced to make further use of analgesics and rehabilitative interventions. A valid treatment would be the surgical stabilization of the fractured vertebra, but often this option might not be considered because of the elderly age of the patients and the hemorrhagic and septic risks. ${ }^{20-22}$ Therefore, it is crucial to predict the early prognosis of the fracture in order to evaluate other strategies - such as khyphoplasty and vertebroplasty-instead of conservative treatment.

\section{CONCLUSIONS}

In conclusion, this study underlines the important role played by the thoraco-lumbar junction, the shape of the fractures, and some MRI STIR sequence patterns in predicting the prognosis of OVFs at an early stage. The swelling and bowshaped fracture types and the STIR MR linear black area might be considered negative prognostic factors for the failure of conservative treatment and the onset of complications such as prolonged back pain, hyperkyphotic deformity, and neurologic deficits. The presence of these factors must be evaluated in the emergency department and may lead to alternative strategies for the treatment of poor prognosis OVF, such as kyphoplasty or vertebroplasty, rather than conservative treatment.

\section{REFERENCES}

1. Chao AS, Chen FP, Lin YC, Huang TS, Fan CM, Yu YW. Application of the World Health Organization fracture risk assessment tool to predict need for dual-energy x-ray absorptiometry scanning in postmenopausal women. Taiwan $J$ Obstet Gynecol. 2015;54(6):722-725.

2. Chen P, Krege JH, Adachi JD, et al. Vertebral fracture status and the World Health Organization risk factors for predicting osteoporotic fracture risk. J Bone Miner Res. 2009;24(3):495-502.

3. Longo UG, Loppini M, Denaro L, Maffulli N, Denaro V. Osteoporotic vertebral fractures: current concepts of conservative care. Br Med Bull. 2012(Jun);102:171-189.

4. Ettinger B, Black DM, Nevitt MC, et al. Contribution of vertebral deformities to chronic back pain and disability. The study of Osteoporotic Fractures Research Group. J Bone Miner Res. 1992;7(4):449-456.

5. Maldague BE, Noel HM, Malghem JJ. The intravertebral vacuum cleft: a sign of ischemic vertebral collapse. Radiology. 1978;129(1):23-29.

6. Feldmann JL, Alcalay M, Queinnec JY, DeBray JM. Spinal cord compression related vertebral osteonecrosis. Clin Exp Rheumatol. 1988;6(3):297-300.

7. Hashimoto K, Yasui N, Yamagishi M, et al. Intravertebral vacuum cleft in the fifth vertebra. Spine. 1989;14(3):351354.

8. Antonacci MD, Mody DR, Rutz K, et al. A histologic study of fractured human vertebral bodies. J Spinal Disord Tech. 2002;15(2):118-126.

9. Baba H, Maezawa Y, Kamitani K, et al. Osteoporotic vertebral collapse with late neurological complications. Paraplegia. 1995;33(5):281-289. 
10. Ito Y, Hasegawa Y, Toda K, Nakahara S. Pathogenesis and diagnosis of delayed vertebral collapse resulting from osteoporotic spinal fracture. Spine J. 2002;2(2):101-106.

11. Omi H, Yokoyama T, Ono A, Numasawa T, Wada K, Fujisawa Y. Can MRI predict subsequent pseudarthrosis resulting from osteoporotic thoracolumbar vertebral fractures? Eur Spine J. 2014;23(12):2705-2710.

12. Sugita M, Watanabe N, Mikami Y, Hase H, Kubo T. Classification of vertebral compression fractures in the osteoporotic spine. J Spinal Disord Tech. 2005;18(4):376-381.

13. Genant $\mathrm{HK}, \mathrm{Wu} \mathrm{CY}$, Nevitt MC, et al. Vertebral fracture assessment using a semiquantitative technique. $J$ Bone Miner Res. 1993;8(9):1137-1148.

14. Muratore M, Ferrera A, Masse A, Bistolfi A. Osteoporotic vertebral fractures: predictive factors for conservative treatment failure. A systematic review. Eur Spine J. 2017;27(10):2565-2576. https://doi.org/10.1007/s00586-0175340-z.

15. Sohn JM, Kim KW, Ha KY, Ha NK, Kim YH, Kim JH. Risk factors for the progressive osteoporotic spinal fracture. $J$ Korean Soc Spine Surg. 2009;16(3):153-159.

16. Ha KY, Kim YH. Risk factors affecting progressive collapse of acute osteoporotic spinal fractures. Osteoporos Int. 2013;24(4):1207-1213.

17. Denis F. The three-column spine and its significance in the classification of acute thoracolumbar spinal injuries. Spine. 1983;8(8):817-831.

18. Yang HL, Wang GL, Niu GQ, et al. Using MRI to determine painful vertebrae to be treated by kyphoplasty in multiple-level vertebral compression fractures: a prospective study. J Int Med Res. 2008;36(5):1056-1063.

19. Gaitanis IN, Hadjipavlou AG, Katonis PG, Tzermiadianos MN, Pasku DS, Patwardhan AG. Balloon kyphoplasty for the treatment of pathological vertebral compressive fractures. Eur Spine J. 2005;14(3):250-260.

20. Gertzbein SD. Scoliosis Research Society. Multicenter spine fracture study. Spine (Phila Pa 1976). 1992;17(5):528540 .
21. Bagnall AM, Jones L, Duffy S, Riemsma RP. Spinal fixation surgery for acute traumatic spinal cord injury. Cochrane Database Syst Rev. 2008;(1):CD004725.

22. Rechtine GR, Bono PL, Cahill D, Bolesta MJ, Chrin AM. Postoperative wound infection after instrumentation of thoracic and lumbar fractures. J Orthop Trauma. 2001;15(8):566-569.

Disclosures and COI: The work has not been published before in any language, is not being considered for publication elsewhere, and has been read and approved by all authors. Each author contributed significantly to one or more aspects of the study. No benefits in any form have been received or will be received from a commercial party related directly or indirectly to the subject of this article. There are no conflicts of interest around this study.

Corresponding Author: Alessandro Bistolfi, MD, Hospital Città della Salute e della Scienza, Department of Orthopaedics, Traumatology, and Rehabilitation, Orthopaedic and Trauma Centre, CTO, Via Zuretti 29, 10126 Turin, Italy. Phone: +39 011 6933573; Fax: +39 011 6933760; Email: abistolfi@cittadellasalute.to.it.

Published 28 August 2020

This manuscript is generously published free of charge by ISASS, the International Society for the Advancement of Spine Surgery. Copyright (c) 2020 ISASS. To see more or order reprints or permissions, see http://ijssurgery.com. 